\title{
Avoidance of Skeletal Muscle Atrophy in Spontaneous and Facultative Hibernators
}

\author{
Clark J. Cotton ${ }^{\star}$ \\ Henry J. Harlow \\ Department of Zoology and Physiology, University of \\ Wyoming, Laramie, Wyoming 82070
}

Accepted 12/6/2009; Electronically Published 3/25/2010

\begin{abstract}
Smooth and skeletal muscle changes were compared from overwintering white-tailed prairie dogs, spontaneous hibernators that undergo regular, low-temperature torpor bouts, and blacktailed prairie dogs, facultative hibernators that use sporadic, moderate-temperature torpor bouts. The objectives were to assess the abilities of these two species with dramatically different torpor patterns (1) to conserve skeletal muscle morphology, protein, and strength and (2) to use labile protein in the small intestine and liver during the winter season of reduced activity and food intake. Mass and protein concentration of the extensor digitorum longus (EDL), soleus, liver, and small intestine, as well as skeletal muscle strength and fiber morphology for the EDL and soleus, were compared before and after hibernation in both species. Both species appeared to be similar to overwintering black bears and underwent very little strength and protein loss, as compared with euthermic models of immobility and long-term fasting. Although the two species used vastly different hibernation strategies, none of the changes in parameters related to muscle atrophy and labile-protein use during the hibernation season differed significantly between them. Therefore, it appears that regardless of the phenotypic expressions of hibernation, the outcome is the conservation of skeletal muscle.
\end{abstract}

\section{Introduction}

Hibernation benefits animals that must cope with cold environments and low food availability through a decreased body temperature and metabolic rate and concomitantly reduced energy needs (Geiser 1998). Despite the corresponding long periods of immobility and reduced food intake associated with torpor, hibernators are resilient to skeletal muscle atrophy, as

\footnotetext{
*Corresponding author; e-mail: ccotton@uwyo.edu.
}

Physiological and Biochemical Zoology 83(3):551-560. 2010. (C) 2010 by The University of Chicago. All rights reserved. 1522-2152/2010/8303-8167\$15.00 DOI: $10.1086 / 650471$ compared with more traditional disuse-atrophy and starvation models (Harlow et al. 2001; Rourke et al. 2004). There is, however, great variation in hibernation strategies, ranging from regular, long torpor bouts with low body temperatures to irregular, short bouts of torpor with moderately depressed body temperatures (Geiser and Ruf 1995). Despite these differences, little research has been conducted to document the relative effectiveness of various hibernation regimes in staving off skeletal muscle atrophy and preserving muscle function. The whitetailed prairie dog (Cynomys leucurus; WTPD) and the blacktailed prairie dog (Cynomys ludovicianus; BTPD) present a unique model for comparing the relative effectiveness of two vastly different hibernation strategies in circumventing the skeletal muscle atrophy typically associated with long periods of immobility and reduced food intake.

Although the WTPD has retained the ancestral expression of spontaneous hibernation, the BTPD appears to have evolved into a facultative hibernator, with reduced expression of torpor. Under laboratory conditions with ad lib. food and water, total darkness, and $4^{\circ} \mathrm{C}$ ambient temperature, WTPDs will initiate regular, low-body temperature torpor bouts in early October (Harlow and Menkens 1986). BTPDs in the laboratory, however, engage in a more facultative torpor, with a moderate reduction in body temperature that can be induced only when animals are completely deprived of food and water at concomitant low ambient temperatures (Harlow and Menkens 1986). Field studies on behavior (Bakko et al. 1988) and body temperature monitoring (Lehmer et al. 2001) of BTPDs support these results. Unlike WTPDs, BTPDs maintain food consumption during the winter months, albeit at a reduced level (Summers and Linder 1978; Harlow 1997). The differences in hibernation strategies between these two species are profound and represent large variances in the extent of immobility and fasting. This study will establish the effectiveness of each hibernation strategy in attenuating skeletal muscle loss.

Prolonged periods of food deprivation and inactivity cause changes in muscle morphology and function for humans and rats. These are typically characterized by a loss of protein (Jagoe et al. 2002; Lecker and Goldberg 2002; Bajotto and Shimomura 2006), a reduction in the cross-sectional area (CSA) of muscle fibers (Rittweger et al. 2005), and a loss of muscle strength (Larsson et al. 1996; Adams et al. 2003). Although the proximate signal may differ between fasting (low insulin/high glucocorticoids) and disuse (lack of neural input), both create a loss of muscle protein due to decreased protein synthesis and increased protein degradation (Lecker and Goldberg 2002). The effects on skeletal muscle locomotor capacity may also vary a great deal between aerobic, fatigue-resistant, slow oxidative (SO) muscles and anaerobic, fatigue-susceptible, fast glycolytic 
(FG) muscles. For example, muscles that are predominantly SO undergo a greater loss of muscle protein and CSA than predominantly FG muscles when they are subjected to disuseatrophy conditions (Widrick et al. 1998), with a concomitant decrease in the SO/FG fiber ratio (Boonyarom and Inui 2006).

Hibernators may be able to circumvent some of the skeletal muscle atrophy associated with periods of reduced activity and starvation. Black bears (Ursus americanus), which enter a continuous state of torpor for up to 5 mo (Harlow et al. 2004), do not suffer appreciable skeletal muscle protein or strength loss (Tinker et al. 1998; Harlow et al. 2001; Lohuis et al. 2007a, $2007 b$ ). Although several studies have suggested that small mammal hibernators suffer some reduction of skeletal muscle protein (Steffen et al. 1991; Wickler et al. 1991), a reduction in fiber CSA (Steffen et al. 1991), and minor changes in fiber ratio (Musacchia et al. 1989; Rourke et al. 2006), no studies have focused on differences in these groups as a function of the depth and duration of torpor. Oxidative stress may determine how successful a hibernator is at preventing skeletal muscle atrophy. Oxidative stress upregulates several degradative pathways associated with skeletal muscle atrophy (Hudson and Franklin 2002; Powers et al. 2005), and increases in oxidative stress have been associated with prolonged, low-temperature torpor bouts (Carey et al. 2000; Harlow and Frank 2001). This might be a factor that causes observed differences in skeletal muscle atrophy between mammals with varying depth and duration of torpor. If oxidative stress during prolonged bouts of torpor influences the profile of skeletal muscle loss, it would be predicted that the BTPD, with short-duration torpor bouts, moderate temperature reduction, and greater activity, may be more resistant to skeletal muscle atrophy during the winter than more traditional hibernators, such as the WTPD.

Another variable that could influence the retention of skeletal muscle morphology and strength by various hibernators would be the differential use of nonskeletal muscle protein. Many vertebrates, including birds (Hobson et al. 1993; Groscolas and Robin 2001), fish (Doucett et al. 1999), and mammals (Yacoe 1983; Torbit et al. 1985), store protein seasonally as a source of energy. These labile-protein reserves appear to be in specific compartments, including the skin (Torbit et al. 1985), blood albumins (García-Rodríguez et al. 1987), muscle (Yacoe 1983; Groscolas and Robin 2001), and viscera (Thompson et al. 1993). Numerous vertebrate species are able to downregulate activity and reduce intestinal size under various conditions of food deprivation, including hibernation (Carey 1990, 1992; Carey and Cooke 1991; Starck 1999; Hume et al. 2002). The liver is also a primary source of labile protein for several hibernators (Vanbeurden 1980; Costanzo 1985; Thompson et al. 1993; Withers and Hillman 2001). Therefore, these reserves may be used by both species of prairie dogs, but to differing extents because of variances in food availability and energy demands.

We therefore proposed two related hypotheses: (1) facultative hibernators would conserve skeletal muscle to a greater extent than spontaneous hibernators because of their greater mobility and lack of oxidative stress associated with prolonged torpor and profound metabolic depression and (2) facultative hiber- nators would exploit labile-protein stores less than spontaneous hibernators because of their opportunity for limited (but significant) nitrogen intake during the winter.

\section{Material and Methods}

All experimental protocols were approved by the University of Wyoming Institutional Animal Care and Use Committee (IACUC A3216-01).

\section{Animal Collection}

BTPDs (four males and seven females, $42^{\circ} 13^{\prime} 00^{\prime \prime} \mathrm{N}$ latitude, $104^{\circ} 42^{\prime} 00^{\prime \prime} \mathrm{W}$ longitude, and 1,340 m elevation) and WTPDs (11 males and 11 females, $41^{\circ} 09^{\prime} 00^{\prime \prime} \mathrm{N}$ latitude, $105^{\circ} 48^{\prime} 00^{\prime \prime} \mathrm{W}$ longitude, and 2,229 $\mathrm{m}$ elevation) were collected in the early fall of 2002 from mixed-grass prairie in eastern and southeastern Wyoming. All of the BTPDs and 11 of the WTPDs (six males and five females) were sampled soon after capture for skeletal muscle strength, protein content, and muscle fibertype morphology of the soleus and the extensor digitorum longus (EDL), as well as liver and intestinal protein content. The EDL and the soleus were chosen because they represent highly FG and SO muscles, respectively, and are widely used in disuse-atrophy studies (Steffen and Musacchia 1984; Desplanches et al. 1987, 2004; Musacchia et al. 1990; Pierno et al. 2007). Because it was impossible to trap WTPDs immediately after their initial emergence from burrows in the spring, the remaining 11 WTPDs (five males and six females) were allowed to enter torpor in the laboratory at a time representing the initiation of their natural circannual hibernation cycle. These 11 animals were housed in $66 \times 30 \times 25-\mathrm{cm}$ cages with nesting material and placed in an environmental chamber at $4^{\circ} \mathrm{C}$ with a 24-h dark cycle and ad lib. food and water. Once the animals entered torpor, food and water were removed. These conditions closely approximated the scenario that WTPDs would endure in the field. Throughout the winter, inspections were made to document the number of animals in torpor and the duration of torpor bouts. Therefore, the date at which these groups began to terminate winter torpor cycles was established. Animals were killed in early March, which coincided with final arousal and emergence of WTPDs in the field. This group of animals was then sampled for protein content, muscle strength, and muscle fiber-type morphology of the soleus and the EDL, as well as the protein content of the small intestine and liver. Eleven additional BTPDs (four males and seven females) were trapped from the field at this same date in early March, which represented a hibernation interval similar to that of the WTPDs in the laboratory. These BTPDs were sampled in a manner identical to that for the laboratory WTPDs. In addition to these animals, we also collected seven WTPDs (five males and two females) and six BTPDs (three males and three females) in the early fall and implanted temperature loggers to confirm differences in hibernation patterns between the two species. 


\section{Hibernation Patterns}

The WTPDs were allowed to acclimate to laboratory conditions for approximately $1 \mathrm{mo}$ with ad lib. food and water and a natural photoperiod. After acclimation, the animals were anesthetized with ketamine hydrochloride $(190 \mathrm{mg} / \mathrm{kg})$ and diazepam $(2.5 \mathrm{mg} / \mathrm{kg})$. A temperature data logger (iButton, Dallas Semiconductor, Dallas, TX), which recorded body temperature every $90 \mathrm{~min}$ to the nearest $0.5^{\circ} \mathrm{C}$, was implanted in the peritoneal cavity. After the animals recovered from surgery, they were placed in an environmental chamber with a 24 -h dark cycle and maintained at $4^{\circ} \mathrm{C}$. The animals were supplied with ad lib. food and water until they entered torpor, at which point food and water were removed from the chamber. Upon final arousal in late winter, the animals were again anesthetized with ketamine chloride and diazepam, and the iButton data loggers were removed. After removal of the iButtons, the animals were killed with an overdose of pentobarbitol. The BTPDs were also anesthetized with ketamine chloride $(190 \mathrm{mg} / \mathrm{kg})$ and diazepam (2.5 $\mathrm{mg} / \mathrm{kg}$ ) and implanted with temperature data loggers, which recorded body temperature every $15 \mathrm{~min}$ to the nearest $0.3^{\circ} \mathrm{C}$ (Tidbit, Onset Computer Corporation, Pocasset, MA). The BTPDs were then released to the trap site after their recovery from anesthesia. These animals were recaptured in late winter at the date corresponding to arousal by WTPDs in the laboratory. After anesthesia, the onset data loggers were removed from the BTPDs and the animals were killed with an overdose of pentobarbitol. Torpor bouts for both species were defined by any continuous drop in temperature from normothermic levels $\left(36^{\circ} \mathrm{C}\right)$ to temperatures below $31^{\circ} \mathrm{C}$ (Lehmer et al. 2003). The end of the torpor bout was defined by a continuous rise in body temperature from below $31^{\circ} \mathrm{C}$ to normothermic levels.

\section{In Vitro Tissue Performance}

Prairie dogs were anesthetized with ketamine hydrochloride $(190 \mathrm{mg} / \mathrm{kg})$ and diazepam $(2.5 \mathrm{mg} / \mathrm{kg})$. The EDL and soleus muscles from the left leg were removed and used for the in vitro strength protocol. After removal of these tissues, the animals were killed with an overdose of pentobarbitol. The EDL and soleus from the right leg, as well as the gastrointestinal tract and liver, were then removed for morphological and protein analyses.

The excised EDL and soleus muscles from the left leg were immediately placed in a myobath apparatus (four-channel MYOBATH, World Precision Instruments, Sarasota, FL) containing oxygenated $\left(95 \% \mathrm{O}_{2}\right.$ and $5 \% \mathrm{CO}_{2}$, perfused through a glass frit) Krebs buffer ( $\mathrm{NaCl} 118.1 \mathrm{mM}, \mathrm{KCl} 3.4 \mathrm{mM}, \mathrm{KH}_{2} \mathrm{PO}_{4}$ $1.2 \mathrm{mM}, \mathrm{MgSO}_{4}^{*} 7 \mathrm{H}_{2} \mathrm{O} 1.0 \mathrm{mM}$, dextrose $10.8 \mathrm{mM}, \mathrm{NaHCO}_{3}$ $25.0 \mathrm{mM}$, and $\left.\mathrm{CaCl}_{2} 2.5 \mathrm{mM}\right)$ at $37^{\circ} \mathrm{C}$. The muscles were attached to a force transducer (Fort-100, World Precision Instruments) and stimulated with a field stimulator (CK-100, CB Sciences, Dover, NH). Optimal twitch responses were obtained by adjusting voltage $(\approx 9 \mathrm{~V})$ and tension on muscle samples. Peak twitch tension/CSA, contraction time, and half-relaxation time were measured using Labscribe software and an iWorx 118 data acquisition box (CB Sciences).

\section{Muscle Morphology}

Muscle samples from the center of the right-leg soleus and EDL of the fall and spring WTPDs and BTPDs were placed in TissueTek OCT imbedding compound (Sakura Finetek USA, Torrance, CA), mounted on cork, and frozen in isopentane cooled by liquid nitrogen. These samples were stored in liquid nitrogen, serially cut into $10-\mu \mathrm{m}$ sections at $-20^{\circ} \mathrm{C}$ with a cryostat (HM505E, Richard-Allen Scientific, Kalamazoo, MI), and stained for myofibrillar ATPase activity with acid incubation at pH 9.4 (Carson 1997). Fibers were classified as FG (light stain) or SO (dark stain) according to Carson (1997). The individual EDL fibers were also measured for CSA with Sigma Scan Pro 5 software (Systat Software, Point Richmond, CA). Soleus muscles, but not EDL muscles, accumulated a significant amount of ice damage and were excluded from fiber CSA analysis.

\section{Protein Analysis}

Muscle samples taken from the right-leg soleus and EDL of fall and spring WTPDs and BTPDs were stored in liquid nitrogen. To determine water content, these samples were later dried in a freeze dryer (Labconco, Kansas City, MO) until no further weight loss occurred. Dry muscle samples were homogenized in phosphate buffer with a tissue homogenizer (Omni 1000, Omni International, Marietta, GA), diluted $1: 20$, and assayed for protein concentration (mg protein/g dry mass) with the Bio-Rad protein assay (Bio-Rad Laboratories, Hercules, CA). Whole-muscle dry mass was used to calculate total protein content for the EDL and soleus.

The small intestine and liver were removed and, in the case of the small intestine, thoroughly flushed and rinsed with physiological saline. Both the small intestine and the liver were then blotted dry and weighed to the nearest $0.1 \mathrm{~g}$. A section of the jejunum (5 cm long) was removed from the small intestine approximately $20 \mathrm{~cm}$ from the beginning of the duodenum. In addition, a triangular piece (approximately $10 \mathrm{~g}$ ) was removed from the liver near the gall bladder. Jejunum and liver samples were freeze-dried, and protein concentrations were determined in a manner identical to that used for skeletal muscle.

\section{Statistical Analyses}

A Mann-Whitney rank sum test was used to analyze hibernation patterns between the two species. A two-way ANOVA, with season and species as the variables, was used to test for differential responses in muscle atrophy, strength loss, and labile-protein use between species during the hibernation season. Tukey's multiple-comparison post hoc test was applied to determine fall/spring differences for each species' muscle atrophy, strength loss, and labile-protein parameters. A separate two-way ANOVA was used to test for differential responses to season for the sexes of each species. Since there were no dif- 
ferences in the interaction between season and sex, all male and female data were pooled together for each species. The data for proportion of SO fibers in the EDL and soleus were arcsine transformed before statistical analysis. The data for EDL FG fiber CSA and liver dry weight were log transformed before the analysis to correct for nonnormal distribution. Likewise, the data for small intestine total protein, in addition to those for soleus strength/CSA, were analyzed on ranks to correct for unequal variance. All statistical analysis was performed with Sigma Stat 3.1 (Systat Software) with significance accepted at $P<0.05$.

\section{Results}

\section{Hibernation Patterns}

The torpor regimes of these two species had distinctively different overall patterns. The WTPDs exhibited regular torpor cycles with very low body temperatures, while the BTPDs had sporadic torpor bouts with much higher minimum temperatures than the WTPDs (Table 1). Of the two species, WTPDs underwent more torpor bouts $(T=21.000, P=0.001)$ that were longer $(T=21.000, P=0.001)$, with lower average minimum temperatures $(T=63.000, P=0.001$; Table 1$)$.

\section{Skeletal Muscle}

Although the soleus for both species lost wet weight over the winter (WTPDs: $q=3.511, P=0.017$; BTPDs: $q=3.216$, $P=0.028)$, there was no change in EDL wet weight for either species (Table 2). The proportion of SO fibers did not change in either the soleus or the EDL over the winter (Table 2). There were also no changes in FG or SO fiber CSA in the EDL of either species over the winter. Soleus total protein content (mg/ muscle) decreased for BTPDs $(q=3.050, P=0.037)$ but not WTPDs $(q=2.246, P=0.120)$ over the winter (Fig. 1$)$. EDL total protein content did not vary seasonally in either species (Fig. 1). Although the EDLs for both species did lose strength/ CSA over the winter (WTPDs: $q=3.337, P=0.023$; BTPDs: $q=3.767, P=0.011$; Fig. 2 ), there was no change in soleus strength for either species (Fig. 2). Contraction time for the WTPD EDL decreased $(q=3.522, P=0.017)$, but the BTPD EDL contraction time did not change $(q=2.802, P=0.055$;
Table 2). There was no seasonal change in contraction time for the soleus or in half-relaxation time for the EDL or soleus in either species. No significant interactions were detected between species and time in the two-way ANOVA tests.

\section{Labile Protein}

Small intestine dry weight decreased in the WTPDs $(q=$ 5.423, $P<0.001)$ and BTPDs $(q=5.423, P<0.001)$ over the winter (Table 2). Liver dry weight also decreased for both species (WTPDs: $q=4.122, P=0.006$; BTPDs: $q=3.191, P=$ 0.030 ) over the winter (Table 2 ). Total protein content of the small intestine declined by approximately $50 \%-70 \%$ for WTPDs and BTPDs (WTPDs: $q=5.323, P<0.001$; BTPDs: $q=7.345, P<0.001$ ) over the winter (Fig. 3), with a concomitant $20 \%-25 \%$ drop in the total protein content of the liver by both species (WTPDs: $q=3.701, P=0.013$; BTPDs: $q=$ 3.589, $P=0.015$ ) over the winter (Fig. 3). No significant interactions were detected between species and time for any of the labile-protein parameters.

\section{Discussion}

The phenotypic expression of hibernation in small mammals has a wide variance from interrupted bouts of prolonged torpor, with body temperatures approaching freezing, to much shorter, intermittent torpor bouts, with body temperatures only $10^{\circ}$ $15^{\circ} \mathrm{C}$ below euthermia (Geiser and Ruf 1995). Some studies have suggested that prolonged torpor bouts at low body temperature in small mammals may be associated with a reduction in skeletal muscle atrophy compared with euthermic-mammal disuse-atrophy models (Steffen et al. 1991; Wickler et al. 1991; Rourke et al. 2006). However, no combined assessment of muscle protein, structure, and strength retention has been conducted on hibernating small mammals that use different torpor strategies. An increased amount of time spent in torpor may dampen the muscle conservation effect of hypometabolism through elevated oxidative stress. This study was conducted to ascertain whether the differences in hibernation patterns by WTPDs and BTPDs correspond to altered patterns of skeletal and smooth muscle retention over the winter.

Table 1: Comparison of hibernation profiles for white-tailed (WTPD) and black-

tailed (BTPD) prairie dogs during the hibernation season

\begin{tabular}{lcccc}
\hline Species & $n$ & No. Torpor Bouts & $\begin{array}{l}\text { Average Duration of } \\
\text { Torpor Bouts }(\mathrm{h})^{\mathrm{b}}\end{array}$ & $\begin{array}{l}\text { Average Minimum } \\
\text { Body Temperature }\left({ }^{\circ} \mathrm{C}\right)^{\mathrm{c}}\end{array}$ \\
\hline WTPD & 7 & $15.0 \pm 1.8$ & $136.6 \pm 8.2$ & $7.0 \pm .4$ \\
BTPD & 6 & $3.0 \pm .3^{*}$ & $30.4 \pm 1.5^{\star}$ & $29.4 \pm .2^{\star}$ \\
\hline
\end{tabular}

Note. Data for the WTPDs are from captive animals, while data from BTPDs are from field animals. All data are represented as means \pm SEM.

a The average number of torpor bouts from November 1 to April 1.

b The average duration (h) from time body temperature first begins to decline until body temperature regains a normothermic level.

${ }^{\mathrm{c}}$ The average minimum body temperature obtained during each individual torpor bout.

* Significant differences between species $(P<0.05)$. 
Table 2: Comparison of skeletal muscle disuse-atrophy indices and labile-protein reserves for white-tailed (WTPD) and black-tailed (BTPD) prairie dogs

\begin{tabular}{lcccc}
\hline & $\begin{array}{l}\text { WTPD Fall } \\
\text { Parameter }\end{array}$ & $\begin{array}{l}\text { WTPD Spring } \\
(n=11)\end{array}$ & $\begin{array}{l}\text { BTPD Fall } \\
(n=11)\end{array}$ & $\begin{array}{l}\text { BTPD Spring } \\
(n=11)\end{array}$ \\
\hline EDL wet weight $(\mathrm{mg})$ & $471 \pm 28.6$ & $407 \pm 23.8$ & $513 \pm 29.6$ & $481 \pm 28.4$ \\
Soleus wet weight $(\mathrm{mg})$ & $320 \pm 13.3$ & $262 \pm 13.6^{*}$ & $384 \pm 16.9$ & $331 \pm 21.2^{\star}$ \\
EDL FG fiber CSA $\left(\mu \mathrm{m}^{2}\right)^{\mathrm{a}}$ & $2,110.8 \pm 82.5$ & $2,007.9 \pm 100.1$ & $2,939.4 \pm 253.0$ & $2,711.9 \pm 134.0$ \\
EDL SO fiber CSA $\left(\mu \mathrm{m}^{2}\right)^{\mathrm{a}}$ & $1,485.1 \pm 78.8$ & $1,472.5 \pm 91.8$ & $2,011.7 \pm 151.0$ & $1,927.3 \pm 110.5$ \\
EDL SO fibers (proportion) & $.106 \pm .015$ & $.077 \pm .006$ & $.122 \pm .013$ & $.102 \pm .007$ \\
Soleus SO fibers (proportion) & $.998 \pm .001$ & $1.000 \pm .000$ & $.997 \pm .003$ & $.999 \pm .001$ \\
EDL contraction time $(\mathrm{ms})^{\mathrm{b}}$ & $23.4 \pm .9$ & $20.5 \pm .6^{*}$ & $24.8 \pm 1.1$ & $22.5 \pm .6$ \\
Soleus contraction time $(\mathrm{ms})^{\mathrm{b}}$ & $64.0 \pm 1.82$ & $60.5 \pm 1.1$ & $59.9 \pm .8$ & $58.4 \pm 1.5$ \\
EDL half-relaxation time $(\mathrm{ms})^{\mathrm{c}}$ & $11.9 \pm .4$ & $11.4 \pm .6$ & $12.9 \pm .5$ & $12.4 \pm .5$ \\
Soleus half-relaxation time $(\mathrm{ms})^{\mathrm{c}}$ & $33.3 \pm 1.4$ & $36.9 \pm 1.6$ & $36.1 \pm .9$ & $39.6 \pm 1.6$ \\
Liver dry weight $(\mathrm{g})$ & $12.308 \pm 1.020$ & $8.982 \pm .621^{\star}$ & $11.679 \pm .999$ & $8.948 \pm .398^{\star}$ \\
Small intestine dry weight $(\mathrm{g})$ & $5.629 \pm .305$ & $3.806 \pm .277^{\star}$ & $5.301 \pm .461$ & $3.484 \pm .266^{*}$ \\
\hline
\end{tabular}

Note. All data are represented as means \pm SEM. EDL $=$ extensor digitorum longus; CSA $=$ cross-sectional area; FG $=$ fast glycolytic muscle; $\mathrm{SO}=$ slow oxidative muscle.

a Fiber CSAs are represented as the means for at least 200 fibers from each skeletal muscle.

${ }^{\mathrm{b}}$ Contraction times indicate the time from beginning of contraction to peak force.

${ }^{\mathrm{c}}$ Half-relaxation times represent the time from peak force to half-peak force.

* Significant differences within species $(P<0.05)$.

\section{Hibernation Patterns}

This study supports the claim that WTPDs in captivity are spontaneous hibernators (Bakko and Nahorniak 1986; Harlow 1997) by reporting regular torpor bouts averaging $5.67 \mathrm{~d}$ and average torpor body temperatures of $7^{\circ} \mathrm{C}$. Although differences in torpor expression exist between laboratory and field conditions, these differences are less pronounced in spontaneous hibernators than in species that use daily torpor (Geiser et al. 2000). Captive WTPDs in our study engaged in torpor bouts that were similar in pattern and minimum body temperature to those of field populations of another spontaneous hibernator, the Utah prairie dog (Cynomys parvidens; Lehmer and Biggins 2005). Therefore, we believe that our captive population closely represents what would be observed in a free-ranging field population. In addition, laboratory studies on BTPDs (Harlow and Menkens 1986) suggest a facultative hibernation profile that coincides closely with the torpor pattern presented in this and other studies of field populations (Lehmer et al. 2003). Here, we report an average bout length of $30.4 \pm 1.51 \mathrm{~h}$ and an average minimum temperature of $29.4^{\circ} \pm 0.16^{\circ} \mathrm{C}$. Therefore, this study supports the hypothesis that BTPDs have a variable or facultative expression for hibernation characterized under most field and laboratory conditions by sporadic torpor bouts of short duration.

\section{Skeletal Muscle}

Remarkably, after 4 mo of spontaneous hibernation by the WTPDs and facultative hibernation by the BTPDs, they both had similar changes in attributes of the skeletal muscles EDL and soleus: wet weight, FG fiber CSA, SO/FG fiber ratio, total protein, contraction time, half-relaxation time, and strength/
CSA. Furthermore, these skeletal muscle changes were comparable to those found in other studies conducted on small mammal hibernators (Musacchia et al. 1989; Steffen et al. 1991; Choi et al. 1998) and bears (Tinker et al. 1998; Harlow et al. 2001; Lohuis et al. 2007a). However, studies on euthermic animals during fasting (Grammeltvedt 1978; Le Maho et al. 1981; Shindoh et al. 1991; Yang and Somero 1993), immobility (Steffen and Musacchia 1984; Desplanches et al. 1987; Elder and McComas 1987; Larsson et al. 1996; Kallainen et al. 2002), and microgravity (Edgerton et al. 1995) all report much higher rates of atrophy and subsequent strength loss than were found in either species of prairie dog in this investigation.

Hibernators may avoid the loss of skeletal muscle by maintaining limited muscle activity and actively managing oxidative stress. Although WTPDs are confined belowground for up to 6 mo of the year, they likely employ vigorous muscle activity during arousal bouts from torpor due to shivering thermogenesis (Mejsnar and Janský 1970; Eddy et al. 2006). BTPDs, in contrast, likely have less muscle activity due to arousal but persist in limited aboveground activity throughout the winter (Tileston 1966; Bakko et al. 1988). Although it is expressed differently in terms of amplitude and duration, the overall amount of muscle activity for both species may be similar and may curtail the potential effects of disuse-induced atrophy (Ferrando et al. 1997; Norman et al. 2000), particularly the preferential loss of SO fibers and muscles (Rourke et al. 2006). The reduction in food intake by both species may also actually stimulate a shift toward more oxidative fibers. As skeletal muscles are exposed to fasting conditions, the ratio of AMP to ATP increases, which prompts a switch to oxidation of fatty acids and subsequently a greater proportion of oxidative fibers (de Lange et al. 2007). 


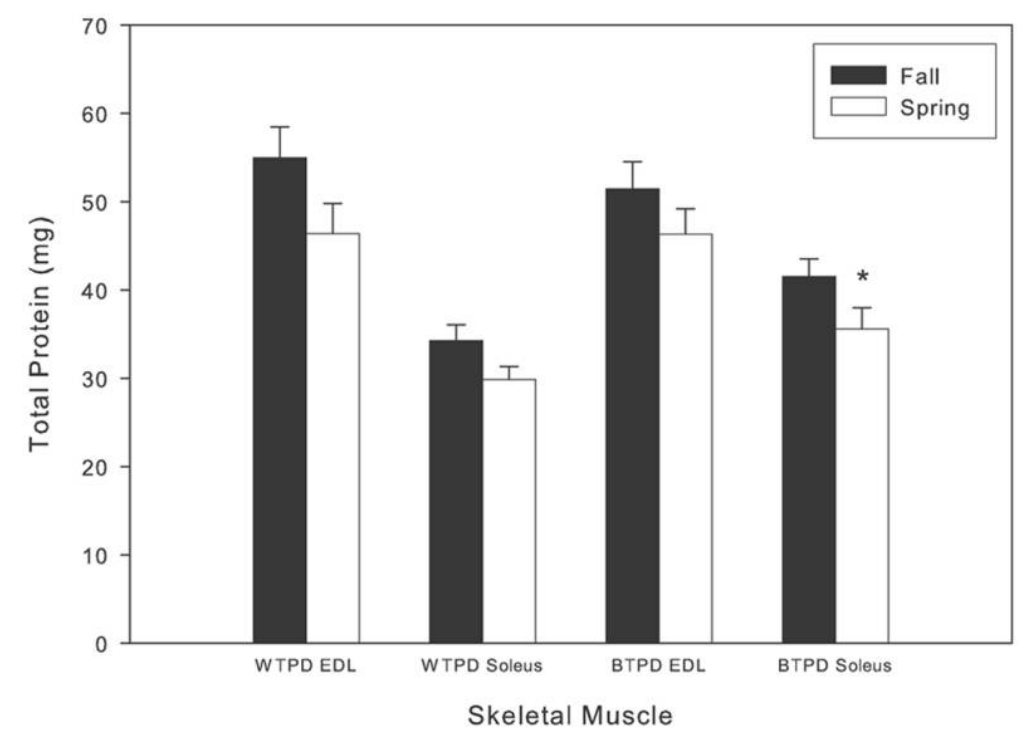

Figure 1. Comparison of extensor digitorum longus (EDL) and soleus whole-muscle protein content for white-tailed (WTPD) and black-tailed (BTPD) prairie dogs. Filled bars denote fall ( $n=11$ for both species), and open bars denote spring $(n=11$ for both species). The asterisk denotes significant difference $(P<0.05)$. Error bars represent SEM. There were no significantly different seasonal responses between species.

The role of oxidative stress in muscle atrophy has been well established as a key upregulator of several important degradative pathways, including the ubiquitin/proteosome system and the calpains (Hudson and Franklin 2002; Powers et al. 2005). Since deep torpor is a significant source of oxidative stress (Carey et al. 2000; Harlow and Frank 2001), the repeated torpor bouts used by the WTPD would seem maladapted to preserving muscle function. But increased levels of antioxidants and heat shock proteins during arousal may attenuate the atrophy associated with oxidative stress (Mamady and Storey 2006; Ohta et al. 2006; Okamoto et al. 2006).

\section{Labile-Protein Reserves}

Even though the major protein source in the body is skeletal muscle, our data suggest that only a modest amount of this protein was catabolized during the winter. We used the average concentration of protein in the EDL and soleus to estimate the total change in protein, assuming that $35 \%$ of total mass is skeletal muscle (Etherton et al. 1982; Harlow 1997). We estimated that overwinter changes in muscle provided an average of $83 \mathrm{~kJ}$, or $0.55 \mathrm{~kJ} / \mathrm{d}$. The modest loss of skeletal muscle is likely supplemented by labile-protein reserves (Le Maho et al.

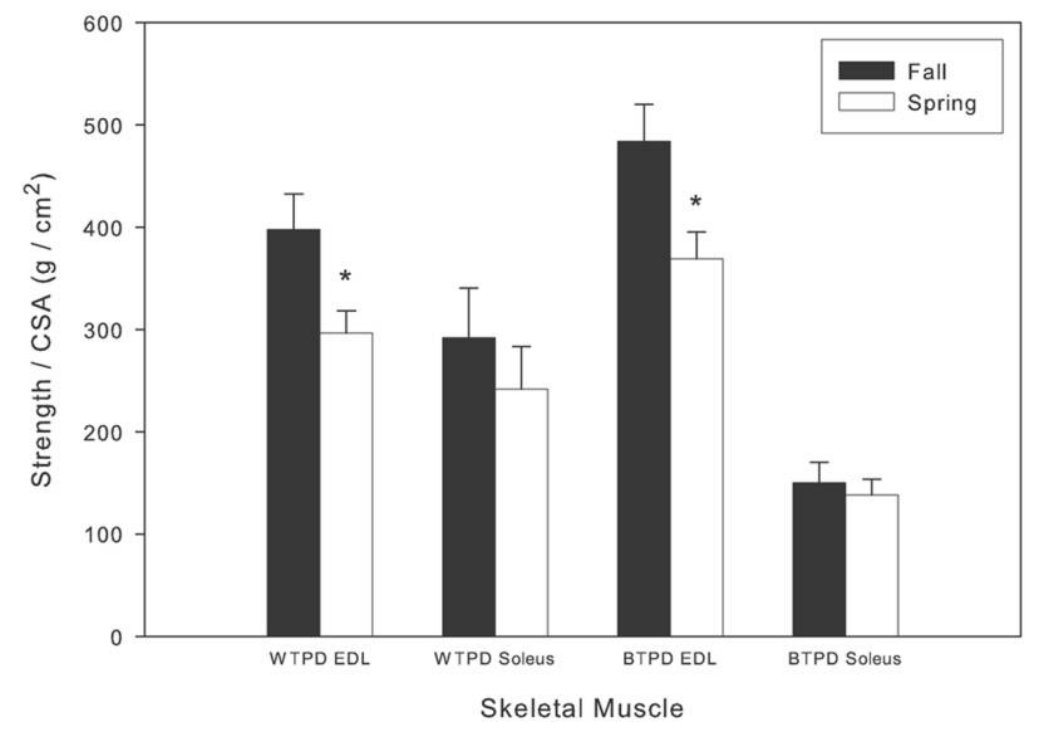

Figure 2. Comparison of extensor digitorum longus (EDL) and soleus muscle strength/CSA $\left(\mathrm{g} / \mathrm{cm}^{2}\right)$ for white-tailed (WTPD) and black-tailed (BTPD) prairie dogs. Filled bars denote fall ( $n=11$ for both species), and open bars denote spring ( $n=11$ for both species). Asterisks denote significant differences $(P<0.05)$. Error bars represent SEM. There were no significantly different seasonal responses between species. 


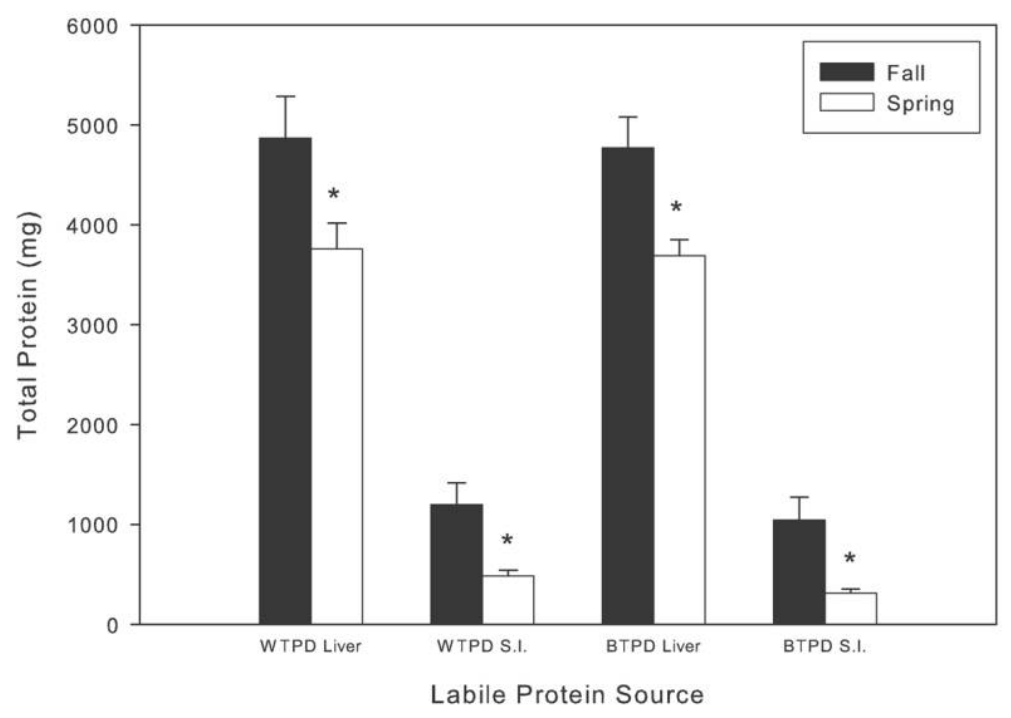

Figure 3. Comparison of small intestine and liver whole-organ protein content for white-tailed (WTPD) and black-tailed (BTPD) prairie dogs. Filled bars denote fall ( $n=11$ for both species), and open bars denote spring ( $n=11$ for both species). Asterisks denote significant differences $(P<0.05)$. Error bars represent SEM. There were no significantly different seasonal responses between species.

1981). For example, BTPDs rely significantly on lean body tissue, especially the liver, for energy during severe cold (Thompson et al. 1993). And small mammal hibernators also lose 50\%$55 \%$ of mucosal mass and protein in the small intestine during hibernation (Carey 1990; Hume et al. 2002). We found similar values of $63.2 \%$ total protein loss in the small intestine and a $22.7 \%$ total protein loss in the liver for prairie dogs. If the changes for small intestine are extrapolated to the entire gastrointestinal tract, these sources of hepatic and intestinal protein add an additional $55 \mathrm{~kJ}$, or $0.37 \mathrm{~kJ} / \mathrm{d}$. The combination of estimated total skeletal muscle and total liver/gastrointestinal tract protein loss would therefore be equivalent to $139 \mathrm{~kJ}, 8 \mathrm{~g}$ of protein, and $1.2 \mathrm{~g}$ of nitrogen (assuming a protein/nitrogen ratio of 6.25 ). This is approximately $18.3 \%$ of our extrapolated values for prehibernation skeletal muscle, liver, and gastrointestinal tract protein. Although the gastrointestinal tract and liver make up only $20 \%$ of our extrapolated prehibernation protein stores, they account for $40 \%$ of protein use during the winter. This may act to spare skeletal muscle protein.

Products other than energy may be influencing protein catabolism by these two species, however. For example, protein breakdown is needed to provide (1) the necessary citric acid cycle intermediates through anaplerotic (feed-in) pathways (Lee and Davis 1979) to allow the continuous beta-oxidation of fatty acids and the concomitant entrance of acetyl coenzyme A into the citric acid cycle; (2) amino acid substrates for gluconeogenesis, particularly during arousal periods (Galster and Morrison 1975); and (3) a positive water balance through the release of bound water. Moreover, relying on fat as a sole energy substrate can impart negative water balance (Bintz et al. 1979; Bintz and Strand 1983). Our extrapolated values for water released from the catabolism of skeletal and nonskeletal protein would amount to $12 \mathrm{~mL}$ over the winter, or $80 \mu \mathrm{L} / \mathrm{d}$ (Bintz et al. 1979). Given the greatly reduced kidney function during the winter, this volume of water may help prevent dehydration (Zatzman 1984). Therefore, the hibernation process does seem to require a certain amount of protein catabolism, especially during arousal periods (Galster and Morrison 1975), to maintain a state of hydration, produce gluconeogenic precursors, and sustain the use of fat. Remarkably, despite differences in torpor strategy, both species of prairie dog appear to have comparable demands on labile-protein depots.

\section{Conclusions}

Both the WTPD and the BTPD are believed to have evolved from a close ancestor of the Gunnison's prairie dog (Cynomys gunisonii), which is a spontaneous hibernator (Pizzimenti 1975). Ten thousand years after spreading into the Great Basin and Great Plains of North America, the WTPD lineage has retained the phenotypic expression for spontaneous hibernation, while the BTPD expresses facultative hibernation. Findings from this study reject the hypothesis that reduced phenotypic expression of torpor offers the BTPD the adaptive advantage of greater skeletal muscle protein and strength retention, as well as conservation of labile-protein reserves, compared with the rigid pattern of torpor used by the WTPD. Despite their vastly different hibernation behavior, the two species lost similar amounts of hepatic, intestinal, and skeletal muscle protein over the winter, with similar skeletal muscle strength retention. The profiles of overwintering changes in skeletal muscle form and function were analogous to those of other hibernators and unlike those of muscle-disuse-atrophy and fasting models. Consequently, we believe that there is a unifying characteristic 
among hibernators, regardless of the depth and duration of torpor, which protects skeletal muscle from atrophy.

\section{Acknowledgments}

We would like to thank Robert M. Carroll for all his help in caring for and maintaining animals for this project. This work was supported in part by NASA Space Grant Consortium NGT40102 and University of Wyoming INBRE (IDeA [Institutional Development Award] Networks for Biomedical Excellence) grant 5P20RR016474.

\section{Literature Cited}

Adams G.R., V.J. Caiozzo, and K.M. Baldwin. 2003. Skeletal muscle unweighting: spaceflight and ground-based models. J Appl Physiol 95:2185-2201.

$\rightarrow$ Bajotto G. and Y. Shimomura. 2006. Determinants of disuseinduced skeletal muscle atrophy: exercise and nutrition countermeasures to prevent protein loss. J Nutr Sci Vitaminol 52:233-247.

$\rightarrow$ Bakko E.B. and J. Nahorniak. 1986. Torpor patterns in captive white-tailed prairie dogs (Cynomys leucurus). J Mammal 67: 576-578.

$\rightarrow$ Bakko E.B., W.P. Porter, and B.A. Wunder. 1988. Body temperature patterns in black-tailed prairie dogs in the field. Can J Zool 66:1783-1789.

$\rightarrow$ Bintz G.L., D.L. Palmer, W.W. Mackin, and F.Y. Blanton. 1979. Selective tissue catabolism and water balance during starvation in Richardson ground squirrels. Comp Biochem Physiol A 64:399-403.

Bintz G.L. and C.E. Strand. 1983. Nitrogen catabolism during starvation and starvation with water deprivation in Richardson ground squirrels. J Comp Physiol 149:565-572.

Boonyarom O. and K. Inui. 2006. Atrophy and hypertrophy of skeletal muscles: structural and functional aspects. Acta Physiol Scand 188:77-89.

Carey H.V. 1990. Seasonal changes in mucosal structure and function in ground squirrel intestine. Am J Physiol 259: R385-R392.

- 1992. Effects of fasting and hibernation on ion secretion in ground squirrel intestine. Am J Physiol 263:R1203R1208.

Carey H.V. and H.J. Cooke. 1991. Effect of hibernation and jejunal bypass on mucosal structure and function. Am J Physiol 261:G37-G44.

$\rightarrow$ Carey H.V., C.L. Frank, and J.P. Seifert. 2000. Hibernation induces oxidative stress and activation of NF- $\kappa$ B in grounc squirrel intestine. J Comp Physiol B 170:551-559.

Carson F.L. 1997. Histotechnology: A Self-Instructional Text. 2nd ed. American Society for Clinical Pathology, Chicago. $\rightarrow$

$\rightarrow$ Choi I.H., Y. Cho, Y.K. Oh, N.P. Jung, and H.C. Shin. 1998. Behavior and muscle performance in heterothermic bats. Physiol Zool 71:257-266.

$\rightarrow$ Costanzo J.P. 1985. The bioenergetics of hibernation in the eastern garter snake Thamnophis sirtalis sirtalis. Physiol Zool 58:682-692.

$\rightarrow$ de Lange P., M. Moreno, E. Silvestri, A. Lombardi, F. Goglia, and A. Lanni. 2007. Fuel economy in food-deprived skeletal muscle: signaling pathways and regulatory mechanisms. FASEB J 21:3431-3441.

Desplanches D., L. Ecochard, B. Sempore, M.H. Mayet-Sornay, and R. Favier. 2004. Skeletal muscle HSP72 response to mechanical unloading: influence of endurance training. Acta Physiol Scand 180:387-394.

Desplanches D., M.H. Mayet, B. Sempore, and R. Flandrois. 1987. Structural and functional responses to prolonged hindlimb suspension in rat muscle. J Appl Physiol 63:558-563.

$\rightarrow$ Doucett R.R., R.K. Booth, G. Power, and R.S. McKinley. 1999. Effects of the spawning migration on the nutritional status of anadromous Atlantic salmon (Salmo salar): insights from stable-isotope analysis. Can J Fish Aquat Sci 56:2172-2180.

$\rightarrow$ Eddy S.F., P.J.R. Morin, and K.B. Storey. 2006. Differential expression of selected mitochondrial genes in hibernating little brown bats, Myotis lucifiugus. J Exp Zool 305A:620-630.

Edgerton V.R., M.-Y. Zhou, Y. Ohira, H. Klitgaard, B. Jiang, G. Bell, B. Harris, et al. 1995. Human fiber size and enzymatic properties after 5 and 11 days of spaceflight. J Appl Physiol 78:1733-1739.

Elder G.C.B. and A.J. McComas. 1987. Development of rat muscle during short-term and long-term hindlimb suspension. J Appl Physiol 62:1917-1923.

Etherton T.D., P.J. Wangsness, V.M. Hammers, and J.H. Ziegler. 1982. Effect of dietary restriction on carcass composition and adipocyte cellularity of swine with different propensities for obesity. J Nutr 112:2314-2323.

Ferrando A.A., K.D. Tipton, M.M. Bamman, and R.R. Wolfe. 1997. Resistance exercise maintains skeletal muscle protein synthesis during bed rest. J Appl Physiol 82:807-810.

Galster W. and P.R. Morrison. 1975. Gluconeogenesis in arctic ground squirrels between periods of hibernation. Am J Physiol 228:325-330.

$\rightarrow$ García-Rodríguez T., M. Ferrer, J.C. Carrillo, and J. Castroviejo. 1987. Metabolic responses of Buteo buteo to long-term fasting and refeeding. Comp Biochem Physiol A 87:381-386.

$\rightarrow$ Geiser F. 1998. Evolution of daily torpor and hibernation in birds and mammals: importance of body size. Clin Exp Pharmacol Physiol 25:736-739.

Geiser F., J.C. Holloway, G. Kortner, T.A. Maddocks, C. Turbill, and R.M. Brigham. 2000. Do patterns of torpor differ between free-ranging and captive mammals and birds? Pp. 95102 in G.K. Heldmaier and M. Klingenspor, eds. Life in the Cold. Springer, New York.

Geiser F. and T. Ruf. 1995. Hibernation versus daily torpor in mammals and birds: physiological variables and classification of torpor patterns. Physiol Zool 68:935-966.

Grammeltvedt R. 1978. Atrophy of a breast muscle with a single fiber type (MX pectoralis) in fasting willow grouse, Lagopus lagopus. J Exp Zool 205:195-204.

Groscolas R. and J.P. Robin. 2001. Long-term fasting and refeeding in penguins. Comp Biochem Physiol A 128:645-655. 
$\rightarrow$ Harlow H.J. 1997. Winter body fat, food consumption, and nonshivering thermogenesis of representative spontaneous and facultative hibernators: the white-tailed prairie dog and black-tailed prairie dog. J Therm Biol 22:21-30.

$\rightarrow$ Harlow H.J. and C.L. Frank. 2001. The role of dietary fatt $\rightarrow$ acids in the evolution of spontaneous and facultative hibernation patterns in prairie dogs. J Comp Physiol B 171:7784.

$\rightarrow$ Harlow H.J., T. Lohuis, R.C. Anderson-Sprecher, and T.D.I $\rightarrow$ Beck. 2004. Body surface temperature of hibernating black bears may be related to periodic muscle activity. J Mammal 85:414-419.

$\rightarrow$ Harlow H.J., T. Lohuis, T.D.I. Beck, and P.A. Iaizzo. 2001. Muscle strength in overwintering bears: unlike humans, bears retain their muscle tone when moribund for long periods. Nature 409:997.

$\rightarrow$ Harlow H.J. and G.E. Menkens. 1986. A comparison of hibernation in the black-tailed prairie dog, white-tailed prairie dog, and Wyoming ground squirrel. Can J Zool 64:793-796.

$\rightarrow$ Hobson K.A., R.T. Alisauskas, and R.G. Clark. 1993. Stablenitrogen isotope enrichment in avian tissues due to fasting and nutritional stress: implications for isotopic analyses of diet. Condor 95:388-394.

Hudson N.J. and C.E. Franklin. 2002. Maintaining muscle mass during extended disuse: aestivating frogs as a model species. J Exp Biol 205:2297-2303.

$\rightarrow$ Hume I.D., C. Bieglbock, T. Ruf, F. Frey-Roos, U. Bruns, and W. Arnold. 2002. Seasonal changes in morphology and function of the gastrointestinal tract of free-living alpine marmots (Marmota marmota). J Comp Physiol B 172:197-207.

$\rightarrow$ Jagoe R.T., S.H. Lecker, M. Gomes, and A.L. Goldberg. 2002. Patterns of gene expression in atrophying skeletal muscles: response to food deprivation. FASEB J 16:1697-1712.

$\rightarrow$ Kallainen L.K., S.S. Jujurikar, L.W. Liang, M.G. Urbanchek, and W.M. Kuzon. 2002. A specific force deficit exists in skeletal muscle after partial denervation. Muscle Nerve 25:31-38.

$\rightarrow$ Larsson L., X.P. Li, H.E. Berg, and W.R. Frontera. 1996. Effects of removal of weight-bearing function on contractility anc $\rightarrow$ myosin isoform composition in single human skeletal muscle cells. Pflueg Arch Eur J Physiol 432:320-328.

$\rightarrow$ Lecker S.H. and A.L. Goldberg. 2002. Slowing muscle atrophy: putting the brakes on protein breakdown. J Physiol 545:729.

Lee S.H. and E.J. Davis. 1979. Carboxylation and decarboxyl $\rightarrow$ ation reactions: anaplerotic flux and removal of citrate cycle intermediates in skeletal muscle. J Biol Chem 254:420-430.

$\rightarrow$ Lehmer E.M. and D.E. Biggins. 2005. Variation in torpor patterns of free-ranging black-tailed and Utah prairie dogs across gradients of elevation. J Mammal 86:15-21.

$\rightarrow$ Lehmer E.M., J.M. Bossenbroek, and B. Van Horne. 2003. The influence of environment, sex, and innate timing mechanisms on body temperature patterns of free-ranging blacktailed prairie dogs (Cynomys ludovicianus). Physiol Biochem Zool 76:72-83.

$\rightarrow$ Lehmer E.M., B. Van Horne, B. Kulbartz, and G.L. Florant $\rightarrow$ R 2001. Facultative torpor in free-ranging black-tailed prairie dogs (Cynomys ludovicianus). J Mammal 82:551-557.
Le Maho Y., H.V.V. Kha, H. Koubi, G. Dewasmes, J. Girard, P. Ferré, and M. Cagnard. 1981. Body composition, energy expenditure, and plasma metabolites in long-term fasting geese. Am J Physiol 241:E342-E354.

Lohuis T.D., H.J. Harlow, and T.D.I. Beck. $2007 a$. Hibernating black bears (Ursus americanus) experience skeletal muscle protein balance during winter anorexia. Comp Biochem Physiol B 147:20-28.

Lohuis T.D., H.J. Harlow, T.D.I. Beck, and P.A. Iaizzo. $2007 b$. Hibernating bears conserve muscle strength and maintain fatigue resistance. Physiol Biochem Zool 80:257-269.

$\rightarrow$ Mamady H. and K.B. Storey. 2006. Up-regulation of the endoplasmic reticulum molecular chaperone GRP78 during hibernation in thirteen-lined ground squirrels. Mol Cell Biochem 292:89-98.

Mejsnar J. and L. Janský. 1970. Shivering and nonshivering thermogenesis in bat (Myotis myotis borkh) during arousal from hibernation. Can J Physiol Pharmacol 48:102-106.

Musacchia X.J., J.M. Steffen, R.D. Fell, and M.J. Dombrowski. 1990. Skeletal muscle response to spaceflight, whole-body suspension, and recovery in rats. J Appl Physiol 69:22482253.

Musacchia X.J., J.M. Steffen, M.C. Steffen, T.E. Geoghegan, and J. Dombrowski. 1989. Morphometric and biochemical adaptations of skeletal muscle in hibernating and non-hibernating ground squirrels, Spermophilus lateralis. Pp. 217-222 in A. Malan and B. Canguilhem, eds. Living in the Cold: 2nd International Symposium. J. Libbey Eurotext, London. Norman T.L., G. Bradley-Popovich, N. Clovis, R.G. Cutlip, and R.W. Bryner. 2000. Aerobic exercise as a countermeasure for microgravity-induced bone loss and muscle atrophy in a rat hindlimb suspension model. Aviat Space Environ Med 71: 593-598.

Ohta H., I. Okamoto, T. Hanaya, S. Arai, T. Ohta, and S. Fukuda. 2006. Enhanced antioxidant defense due to extracellular catalase activity in Syrian hamster during arousal from hibernation. Comp Biochem Physiol C 143:484-491.

Okamoto I., T. Kayano, T. Hanaya, S. Arai, M. Ikeda, and M. Kurimoto. 2006. Up-regulation of an extracellular superoxide dismutase-like activity in hibernating hamsters subjected to oxidative stress in mid- to late arousal from torpor. Comp Biochem Physiol C 144:47-56.

Pierno S., J.F. Desaphy, A. Liantonio, A. De Luca, A. Zarrilli, L. Mastrofrancesco, G. Procino, G. Valenti, and D.C. Camerino. 2007. Disuse of rat muscle in vivo reduces protein kinase C activity controlling the sarcolemma chloride conductance. J Physiol 584:983-995.

Pizzimenti J.J. 1975. Evolution of the Prairie Dog Genus Cynomys. Museum of Natural History, University of Kansas, Lawrence.

Powers S.K., A.N. Kavazis, and K.C. DeRuisseau. 2005. Mechanisms of disuse muscle atrophy: role of oxidative stress. Am J Physiol 288:R337-R344.

Rittweger J., H.M. Frost, H. Schiessl, H. Ohshima, B. Alkner, P. Tesch, and D. Felsenberg. 2005. Muscle atrophy and bone loss after 90 days' bed rest and the effects of flywheel resistive 
exercise and pamidronate: results from the LTBR study. Bone 36:1019-1029.

$\rightarrow$ Rourke B.C., C.J. Cotton, H.J. Harlow, and V.J. Caiozzo. $2006 \rightarrow$ Maintenance of slow type I myosin protein and mRNA expression in overwintering prairie dogs (Cynomys leucurus and ludovicianus) and black bears (Ursus americanus). J Comf Physiol B 176:709-720.

$\rightarrow$ Rourke B.C., Y. Yokoyama, W.K. Milsom, and V.J. Caiozzo. 2004. Myosin isoform expression and MAFbx mRNA level: in hibernating golden-mantled ground squirrels (Spermophilus lateralis). Physiol Biochem Zool 77:582-593.

Shindoh C., A. Dimarco, W. Lust, and G. Supinski. 1991. Effect of acute fasting on diaphragm strength and endurance. Am Rev Respir Dis 144:488-493.

Starck J.M. 1999. Structural flexibility of the gastro-intestinal tract of vertebrates: implications for evolutionary morphology. Zool Anz 238:87-101.

$\rightarrow$ Steffen J.M., D.A. Koebel, X.J. Musacchia, and W.K. Milsom. 1991. Morphometric and metabolic indexes of disuse in muscles of hibernating ground squirrels. Comp Biochem Physio B 99:815-819.

Steffen J.M. and X.J. Musacchia. 1984. Effect of hypokinesia and hypodynamia on protein, RNA, and DNA in rat hindlimb muscles. Am J Physiol 247:R728-R732.

$\rightarrow$ Summers C.A. and R.L. Linder. 1978. Food-habits of blacktailed prairie dog in western South Dakota. J Range Manag 31:134-136.

Thompson T.A., M.W. Agar, and G.L. Bintz. 1993. Lipid deposition and use by black-tailed prairie dogs, Cynomys ludovicianus, in the natural environment. Physiol Zool 66:561579.

\footnotetext{
$\rightarrow$ Tileston J.V. 1966. Some comparisons of the black-tailed (Cyn
} omys ludovicianus) and white-tailed prairie dogs (Cynomys leucurus) in north-central Colorado. Am Midl Nat 75:292316.

Tinker D.B., H.J. Harlow, and T.D.I. Beck. 1998. Protein use and muscle-fiber changes in free-ranging, hibernating black bears. Physiol Zool 71:414-424.

$\rightarrow$ Torbit S.C., L.H. Carpenter, D.M. Swift, and A.W. Alldredge. 1985. Differential loss of fat and protein by mule deer during winter. J Wildl Manag 49:80-85.

Vanbeurden E.K. 1980. Energy-metabolism of dormant Australian water-holding frogs (Cyclorana platycephalus). Copeia 1980:787-799.

Wickler S.J., D.F. Hoyt, and F. Vanbreukelen. 1991. Disuse atrophy in the hibernating golden-mantled ground-squirrel, Spermophilus lateralis. Am J Physiol 261:R1214-R1217.

Widrick J.J., K.M. Norenberg, J.G. Romatowski, C.A. Blaser, M. Karhanek, J. Sherwood, S.W. Trappe, T.A. Trappe, D.L. Costill, and R.H. Fitts. 1998. Force-velocity-power and force$\mathrm{pCa}$ relationships of human soleus fibers after 17 days of bed rest. J Appl Physiol 85:1949-1956.

Withers P.C. and S.S. Hillman. 2001. Allometric and ecological relationships of ventricle and liver mass in anuran amphibians. Funct Ecol 15:60-69.

Yacoe M.E. 1983. Protein metabolism in the pectoralis muscle and liver of hibernating bats, Eptesicus fuscus. J Comp Physiol 152:137-144.

Yang T.-H. and G.N. Somero. 1993. Effects of feeding and food deprivation on oxygen consumption, muscle protein concentration and activities of energy metabolism enzymes in muscle and brain of shallow-living (Scorpaena guttata) and deep-living (Sebastolobus alascanus) scorpaenid fishes. J Exp Biol 181:213-232.

Zatzman M.L. 1984. Renal and cardiovascular effects of hibernation and hypothermia. Cryobiology 21:593-614. 